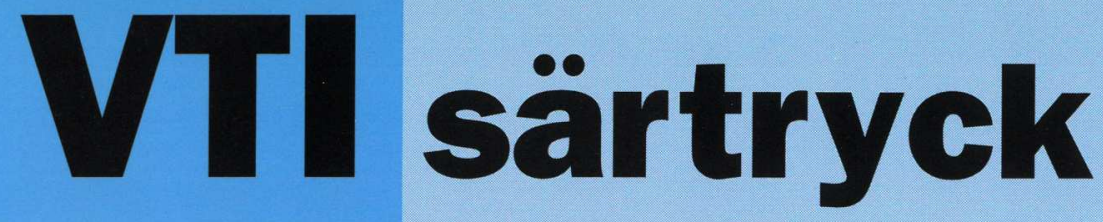

Nr $220 \bullet 1994$

The VTI Flat Bed Tyre Test Facility

- A New Tool for Testing Commercial Tyre Characteristics

\title{
Olle Nordström
}

Reprint from SAE Technical Paper Series, SP 1003 - The Influence of Tire, Axle and Brake Characteristics on Truck Braking and Steering Performance, paper 933006, pp 13-23 (International Truck and Bus Meeting and Exposition, Detroit, Michigan, November 1-4, 1993)

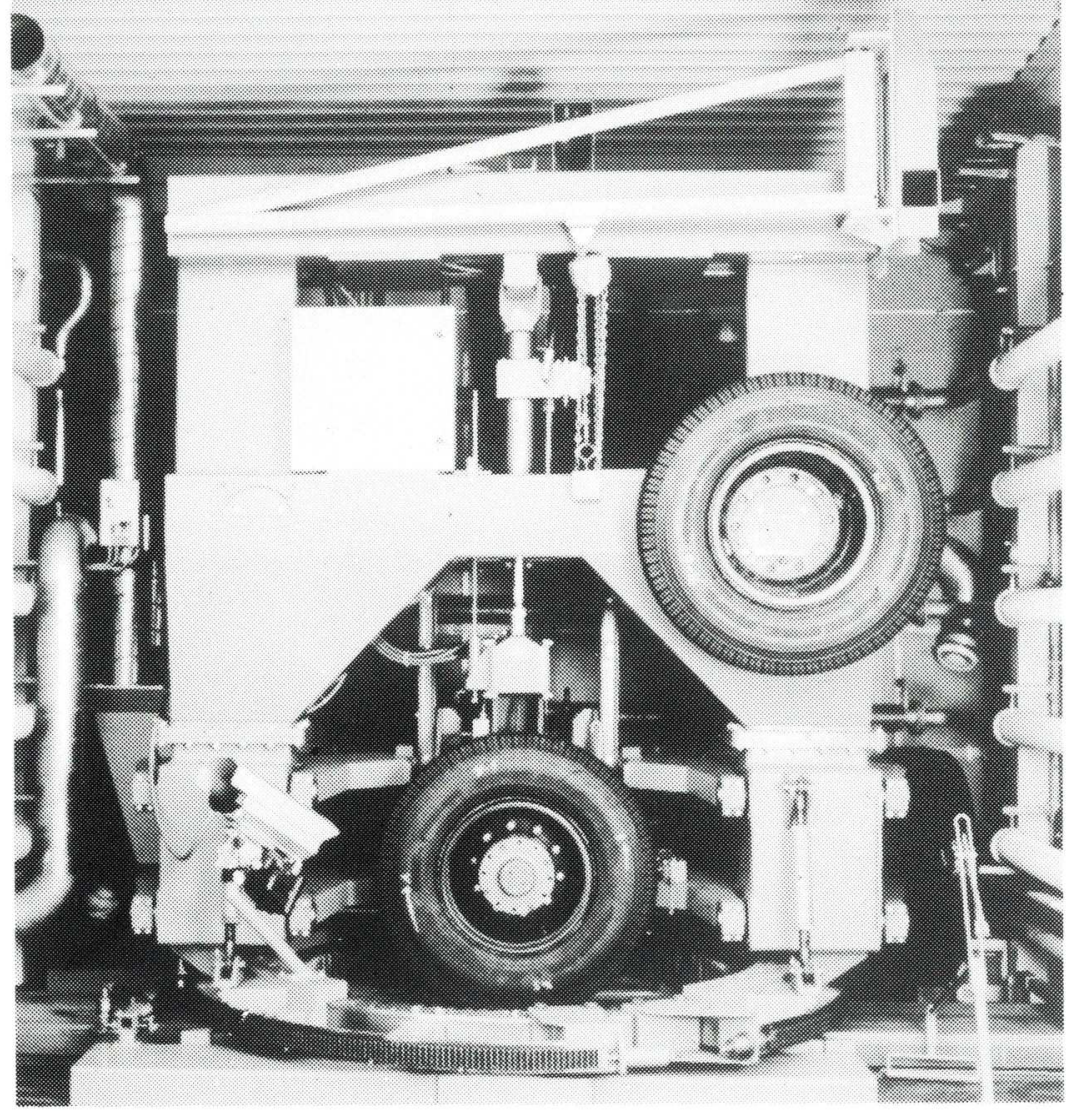

As 



\section{VTI särtryck}

Nr $220 \bullet 1994$

\section{The VTI Flat Bed Tyre Test Facility}

- A New Tool for Testing Commercial Tyre Characteristics

\section{Olle Nordström}

Reprint from SAE Technical Paper Series, SP 1003

- The Influence of Tire, Axle and Brake Characteristics on Truck Braking and Steering Performance, paper 933006, pp 13-23 (International Truck and Bus Meeting and Exposition, Detroit, Michigan, November 1-4, 1993) 


\section{Revise text on page 22}

Figure 14 Example of result from measurement of lateral friction on ice with a $315 / 80 \mathrm{R}$ 22.5 truck tyre at $60 \mathrm{kN}$ wheel load and 8 bar inflation pressure at $30 \mathrm{~km} / \mathrm{h}$

\section{Revise text on page 23}

Figure 15 Example of result from measurement of combined lateral and braking friction with a $315 / 80$ R 22.5 truck tyre on the high friction test track steel surface at $40 \mathrm{kN}$ wheel load and 8 bar inflation pressure at $30 \mathrm{~km} / \mathrm{h}$. 


\section{The VTI Flat Bed Tyre Test Facility - A New Tool for Testing Commercial Tyre Characteristics}

Olle Nordström

Swedish Road and Transport Research Institute

Reprinted from: The Influence of Tire, Axle, and Brake Characteristics on Truck Braking and Steering Performance

(SP-1003) 
The appearance of the ISSN code at the bottom of this page indicates SAE's consent that copies of the paper may be made for personal or internal use of specific clients. This consent is given on the condition, however, that the copier pay a $\$ 5.00$ per article copy fee through the Copyright Clearance Center, Inc. Operations Center, 27 Congress St., Salem, MA 01970 for copying beyond that permitted by Sections 107 or 108 of the U.S. Copyright Law. This consent does not extend to other kinds of copying such as copying for general distribution, for advertising or promotional purposes, for creating new collective works, or for resale.

SAE routinely stocks printed papers for a period of three years following date of publication. Direct your orders to SAE Customer Sales and Satisfaction Department.

Quantity reprint rates can be obtained from the Customer Sales and Satisfaction Department.

To request permission to reprint a technical paper or permission to use copyrighted SAE publications in other works, contact the SAE Publications Group.

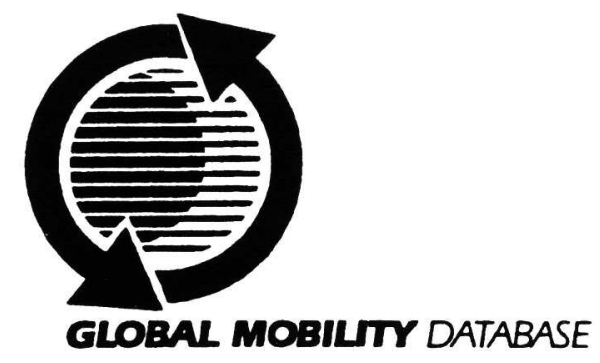

All SAE papers, standards, and selected books are abstracted and indexed in the SAE Global Mobility Database.

No part of this publication may by reproduced in any form, in an electronic retrieval system or otherwise, without the prior written permission of the publisher.

\section{ISSN 0148-7191}

Copyright 1993 Society of Automotive Engineers, Inc.

Positions and opinions advanced in this paper are those of the author(s) and not necessarily those of SAE. The author is solely responsible for the content of the paper. A process is available by which discussions will be printed with the paper if it is published in SAE transactions. For permission to publish this paper in full or in part, contact the SAE Publications Group.

Persons wishing to submit papers to be considered for presentation or publication through SAE should send the manuscript or a 300 word abstract of a proposed manuscript to: Secretary, Engineering Activity Board, SAE. 


\title{
The VTI Flat Bed Tyre Test Facility - A New Tool for Testing Commercial Tyre Characteristics
}

\author{
Olle Nordström \\ Swedish Road and Transport Research Institute
}

\begin{abstract}
An indoor climate controlled high speed flat bed tyre test facility has been developed primarily for testing on ice. High friction tests are also possible. Braking and steering characteristics of heavy truck and car tyres can be measured. The facility has a stationary test wheel rig that rotates 90 degrees and a $55 \mathrm{~m}$ long moving steel track. The maximum speed is $40 \mathrm{~km} / \mathrm{h}$. Motions and wheel load are operated by computer controlled hydraulic actuators. Results from heavy truck tyre measurements on ice and dry steel show good correlation with vehicle tests. Passenger car tyres have also been successfully tested.
\end{abstract}

\section{INTRODUCTION}

The traffic safety of heavy commercial vehicles has been one of the priority items for research funding for the Swedish Government since more than 20 years. In Sweden substantial transportation with heavy duty vehicles is carried out on ice and snow covered roads for several months every winter season. Good friction between tyre and road is essential for safe and efficient traffic. Tyres with best possible adhesion under these conditions should therefore be promoted. For this purpose performance based winter tyre qualification criteria are desirable.

To obtain objective valid and repeatable testing of tyres on icy road surfaces is however a complicated and expensive task. A major difficulty is the weather conditions during outdoor testing. An indoor climate controlled test facility was therefore regarded as necessary for efficient research and testing. Sponsored first by the Swedish Board for Technical Development and later by direct Government funding VTI has therefore developed a truck tyre test facility for indoor testing on ice surfaces. The specification did however also cover testing of passenger car tyres and tests under high friction conditions. The facility became operational in 1989 for Government sponsored testing of road grip on ice for passenger car tyres of different types with and without studs. Since then testing has been concentrated on truck tyre braking and steering friction tests on ice mostly for truck and tyre manufacturers.

\section{APPLICATIONS OF USE}

Some of the expected applications of use of the facility are :

- tyre data for research on handling and braking of road vehicles by means of computer simulations and driving simulator experiments

-consumer information about friction properties of tyres, primarily on ice

- the development of functional qualification performance criteria for winter tyres and tyre studs

- routine testing of tyres and tyre studs

- research and development testing of new tyre designs, tread compounds and tread patterns

- research and development testing of new studs and other anti skid devices

- research on the influence of ice characteristics on the tyre/ice friction

\section{THE TEST FACILITY}

The facility has a stationary tyre test rig and a moving flat test road surface. The equipment is enclosed in a special climate controlled building, The road surface is separately refrigerated. A general view of the facility is given in figure 1.

TYRE TEST RIG - The tyre test rig that is shown in figure 2 and 3 consists of a steel frame with double wishbone wheel suspension resting on a large central roller bearing which enables the frame with test 

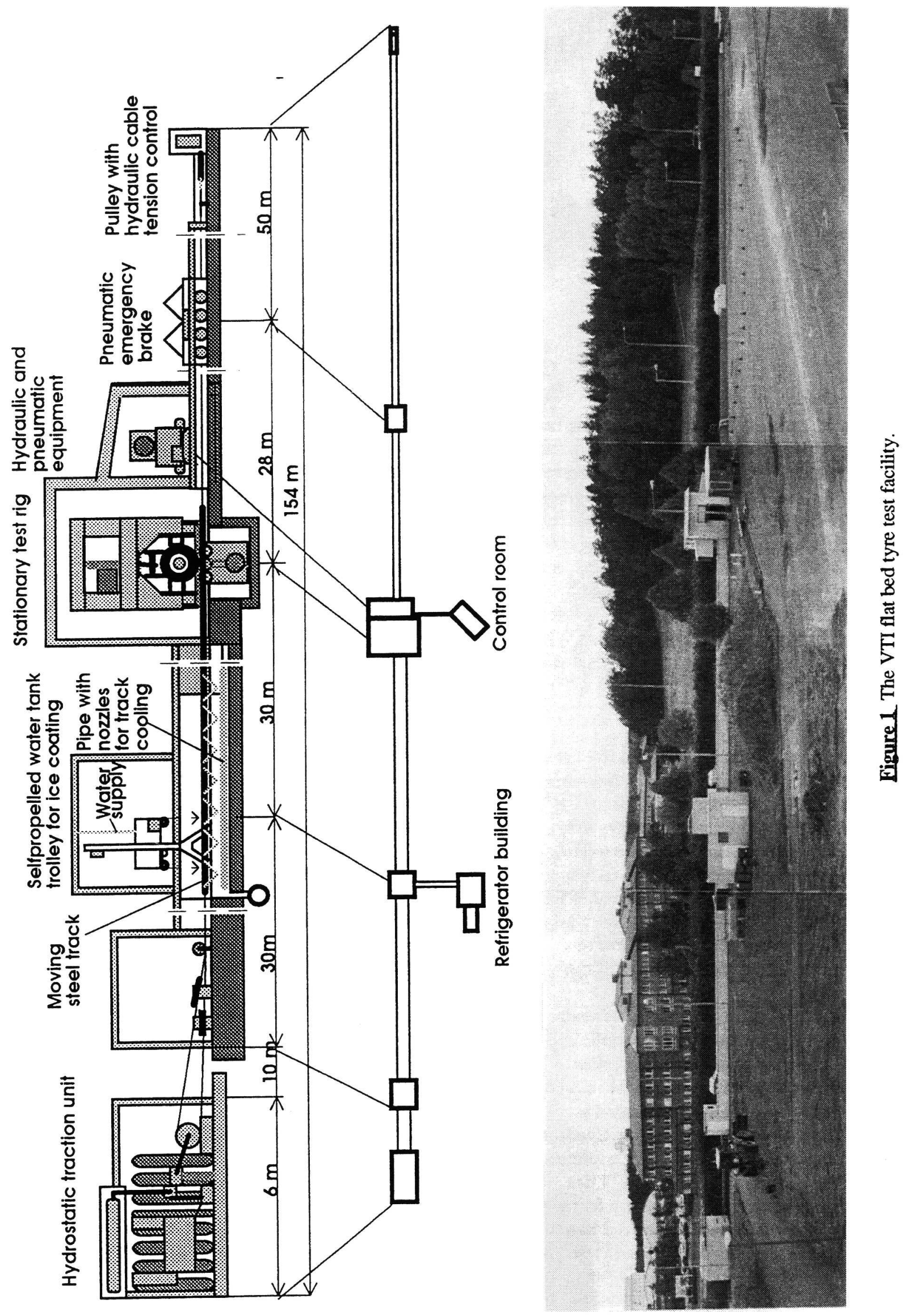


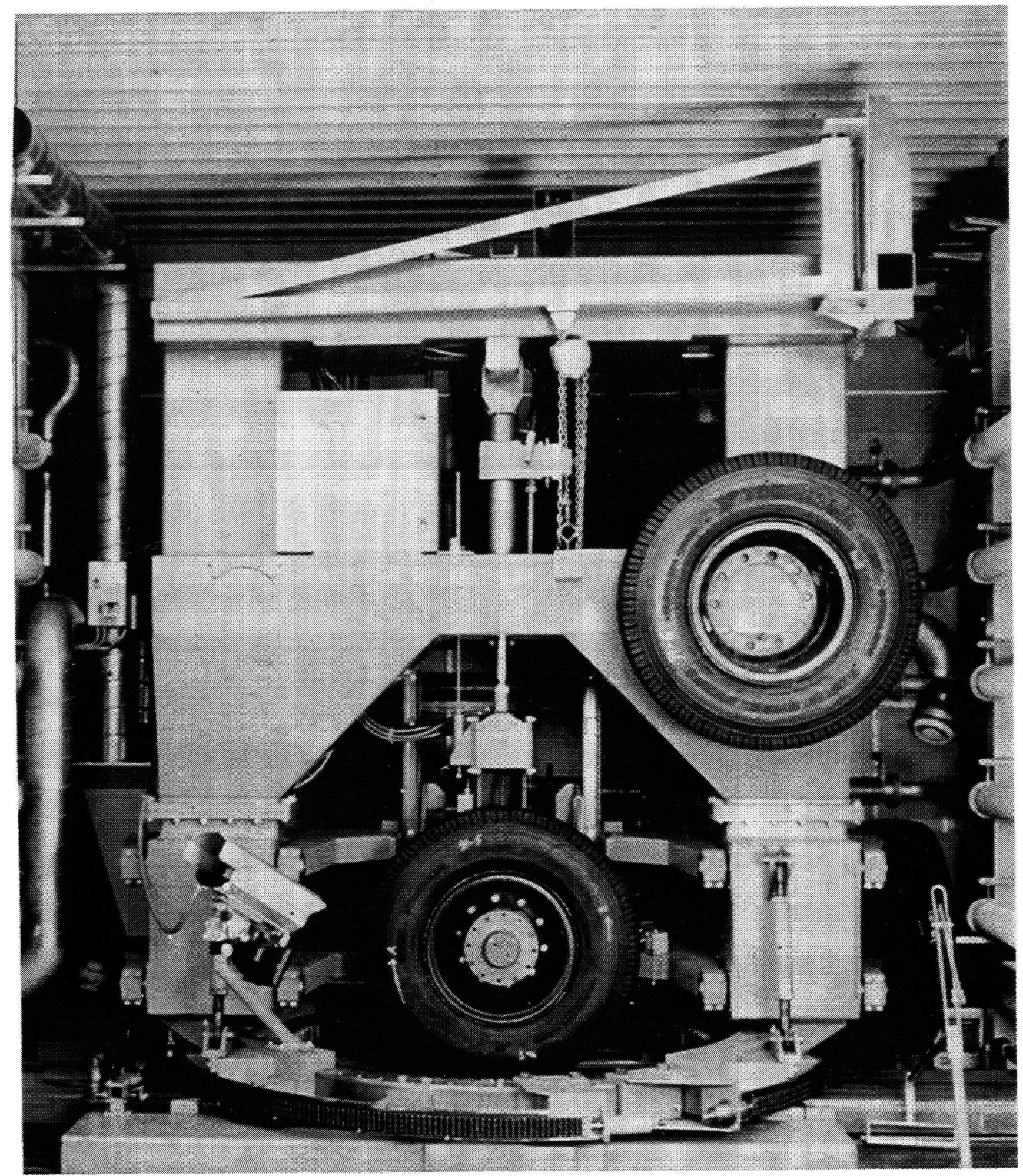

Eigure 2 Tyre test rig. Front view 

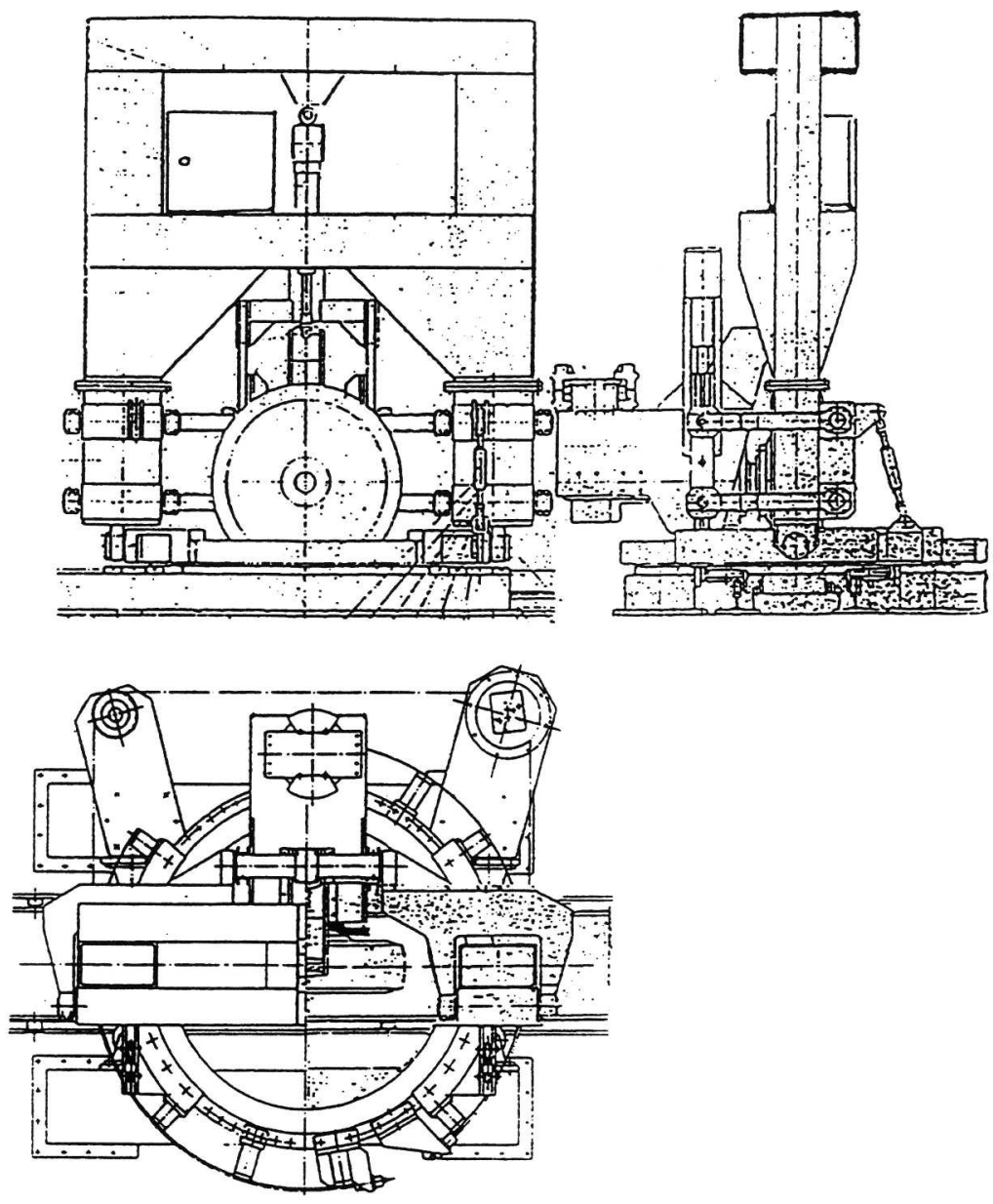

Figure 3. Test wheel rig. Front, side and top view

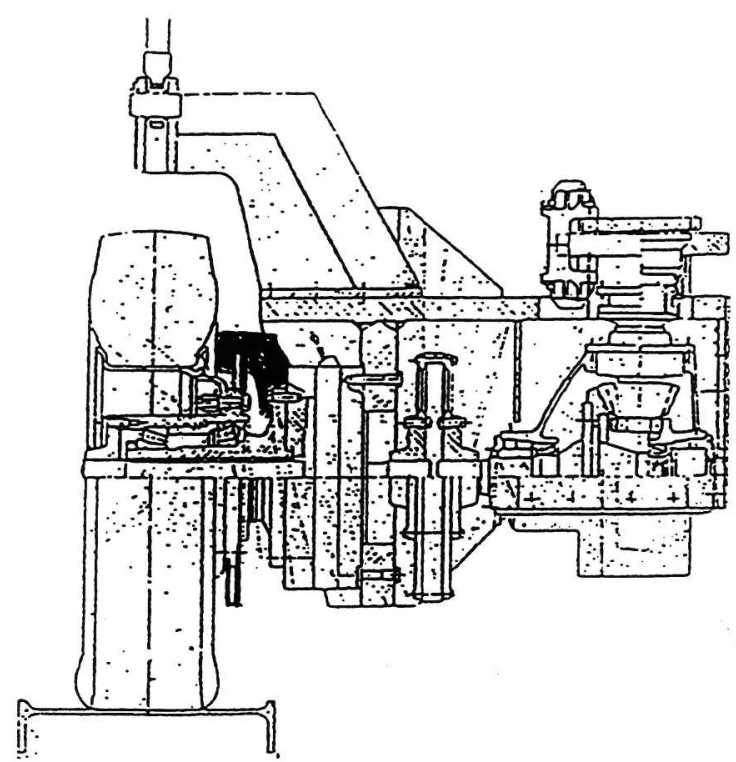

Figure 4. Sub frame with test wheel hub, force transducer and brake system 
wheel to be rotated around a vertical axis through the centre of the test wheel for steering tests.

The side slip angle - The side slip angle can be controlled from $90^{\circ}$ right hand to $30^{\circ}$ left hand steering angle at angular velocities up to 30 degrees per second by means of a computer controlled hydraulic motor.

The camber angle - The camber angle can be adjusted manually $10^{\circ}$ in both directions by tilting the frame including the force transducer system relative to the plane of slip angle rotation.

Wheelload- Wheel loads up to $100 \mathrm{kN}$ are applied by means of a computer controlled hydraulic cylinder. Force and position feed back is available.

Braking system - Two disc brakes can be used for truck tyre testing (figure 4). One is more powerful than the other. The most powerful brake amplifies its braking torque 4 times in a gear box and transmits this braking torque via a shaft that runs through a hole in the centre of the force transducer to the wheel hub. The other brake disc is directly attached to the hub and the caliper to the force transducer plate closest to the wheel. The reason for using two brakes is that self-induced oscillations can occur due to stick-slip resonance in the torsion shaft at very low speeds. These are efficiently damped by the hub brake which by itself is sufficient for low friction measurements. The brakes are hydraulic but are actuated by a pneumatic booster. When car tyres are tested a special wheel suspension and hub with a standard car disc brake is used.

Hydraulic and pneumatic power supply - The hydraulic power for side slip motion and wheel load is supplied by an electrically driven pump/accumulator unit.

The wheel brake is powered by an electrically driven pneumatic compressor/accumulator unit. Both units are installed in a room next to the test rig room.

Wheel force and moment measurement - The forces and moments acting on the test wheel are measured by means of a triaxial force and moment transducer consisting of four triaxial KISTLER piezoelectric transducers prestressed in compression between two stainless steel plates. The test wheel hub is mounted on one of the plates and the other is attached to a sub frame carrying the main braking system (figure 4). The measured forces together with geometric relations make it possible to measure both forces and moments acting on the test wheel. The measuring ranges for the forces are from 0 to $100000 \mathrm{~N}$ vertical and up to 70000 $\mathrm{N}$ for the lateral and longitudinal forces. The signals are first processed in a one card computer positioned in a temperature controlled box on the test rig together with the special KISTLER amplifier system and then sent in digital format to a $486 \mathrm{PC}$ in the control room for further processing.

Test wheel shifting - The operation of shifting from one test wheel to the next can be carried out by one man by the help of a manually operated winch and an air operated nut runner (figure 5). The operation normally takes less than 10 minutes.

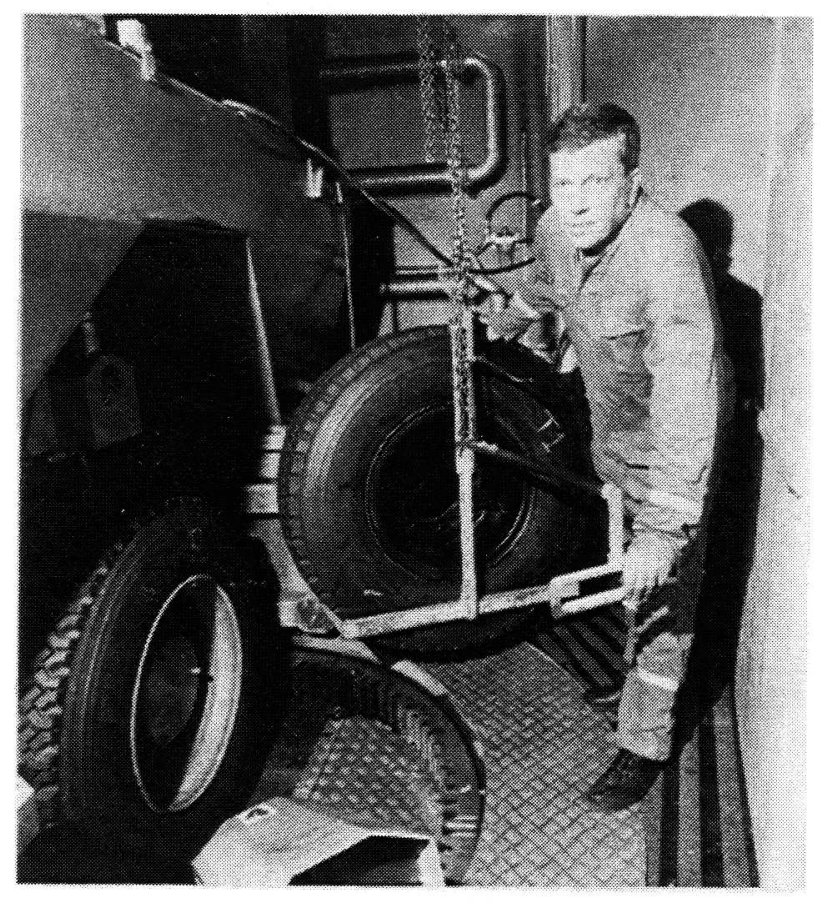

Eigure 5. One man shifting of test wheels with a manually operated winch.

MOVING TEST TRACK SYSTEM - The road surface is represented by a flat steel beam test track with a length of $55 \mathrm{~m}$ and a width of $0.6 \mathrm{~m}$. The beam, which is supported by small steel wheels, travels along an approximately $130 \mathrm{~m}$ long steel rail track. The part of the beam that is below the test wheel is supported by three steel rollers contained in the base of the test rig. (These rollers can be driven by an electric motor at a speed of 30 $\mathrm{km} / \mathrm{h}$ for conditioning of the test tyre when the track is run to an end position which leaves the rollers free to support the test tyre directly.)

Test track propulsion system - The test track is pulled by a steel cable winch with two hydraulic motors directly attached to a cable drum ( figure 6). Each end of the moving test track is connected to the drum with a cable. The cables are guided vertically and laterally from the track level to the drum with a pulley system (figure 7). One of the cables is linked 180 degrees over a pulley which transmits a prestressing force of $80000 \mathrm{~N}$ to the cable. The required force of $160000 \mathrm{~N}$ on the pulley hub is generated by a hydraulic cylinder with a 


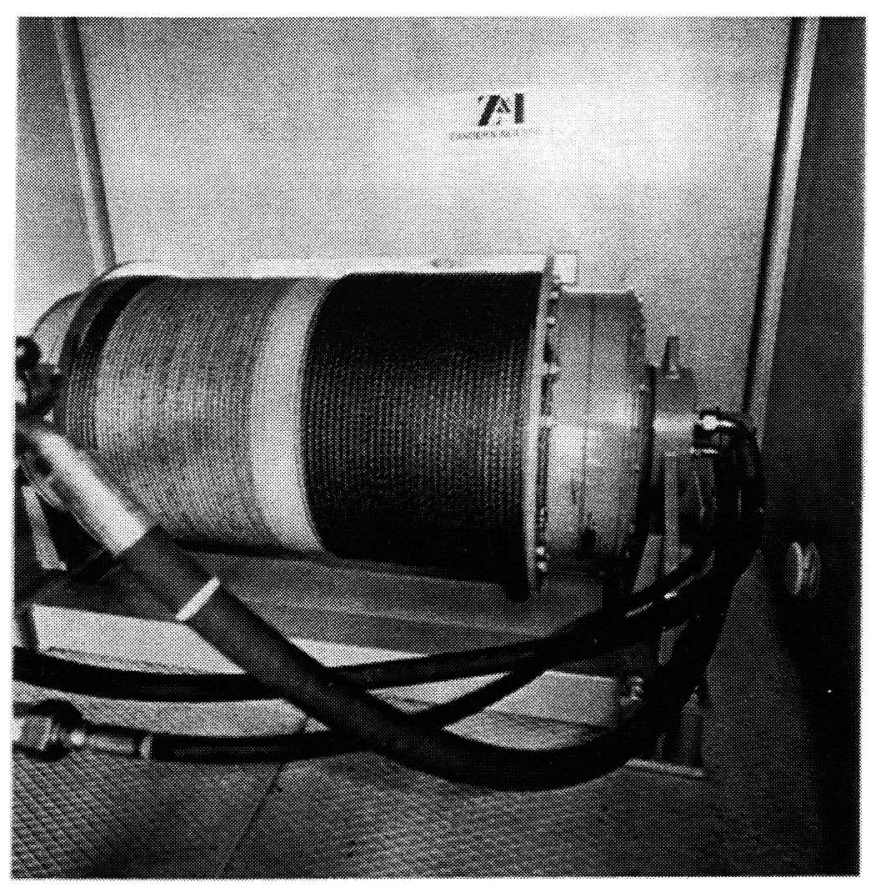

Eigure 6 Cable drum with hydraulic motors

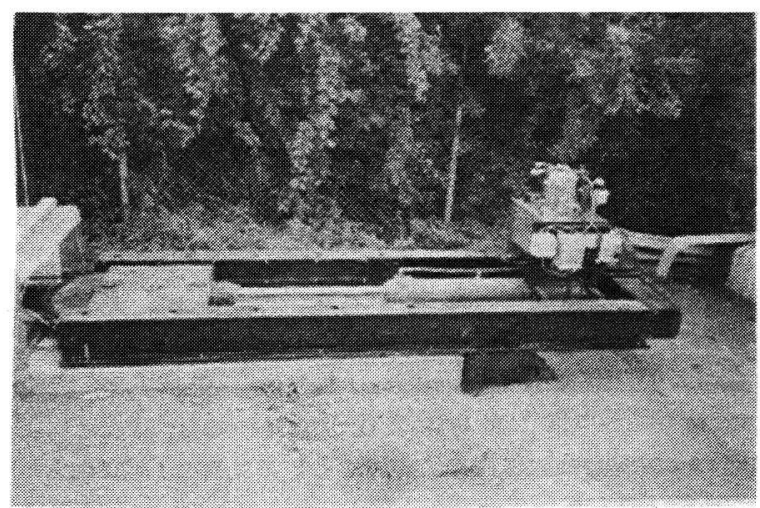

Eigure 8 Pulley with hydraulic tension force control

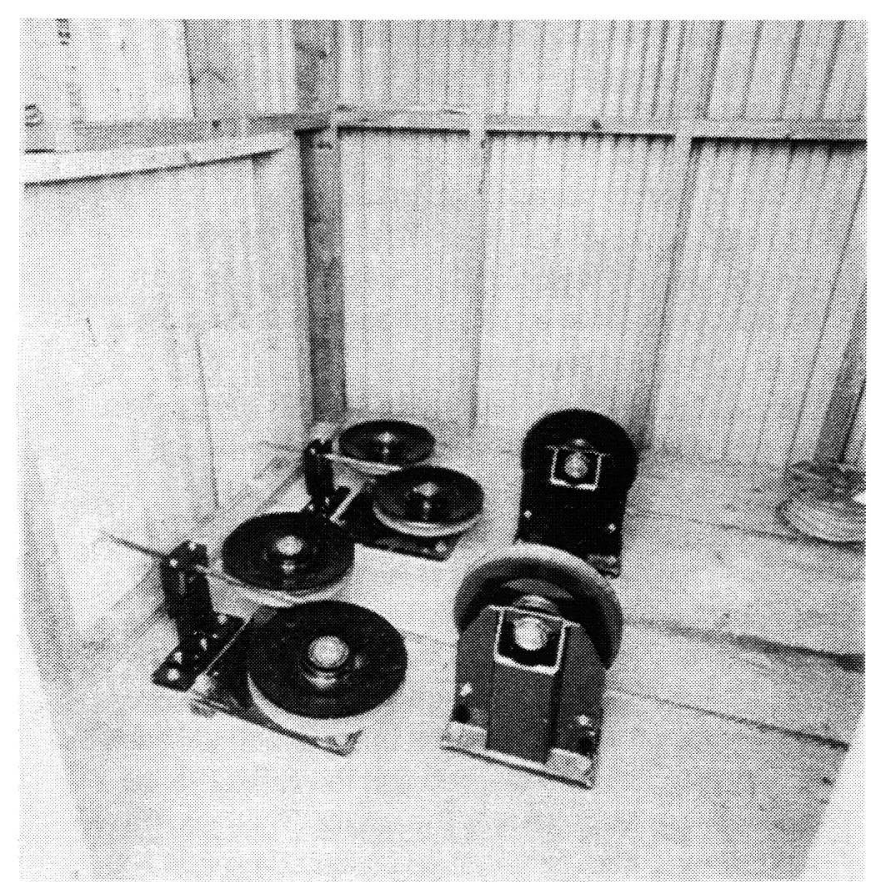

Eigure 7 Pulley system for cable guidance between. drum and track .

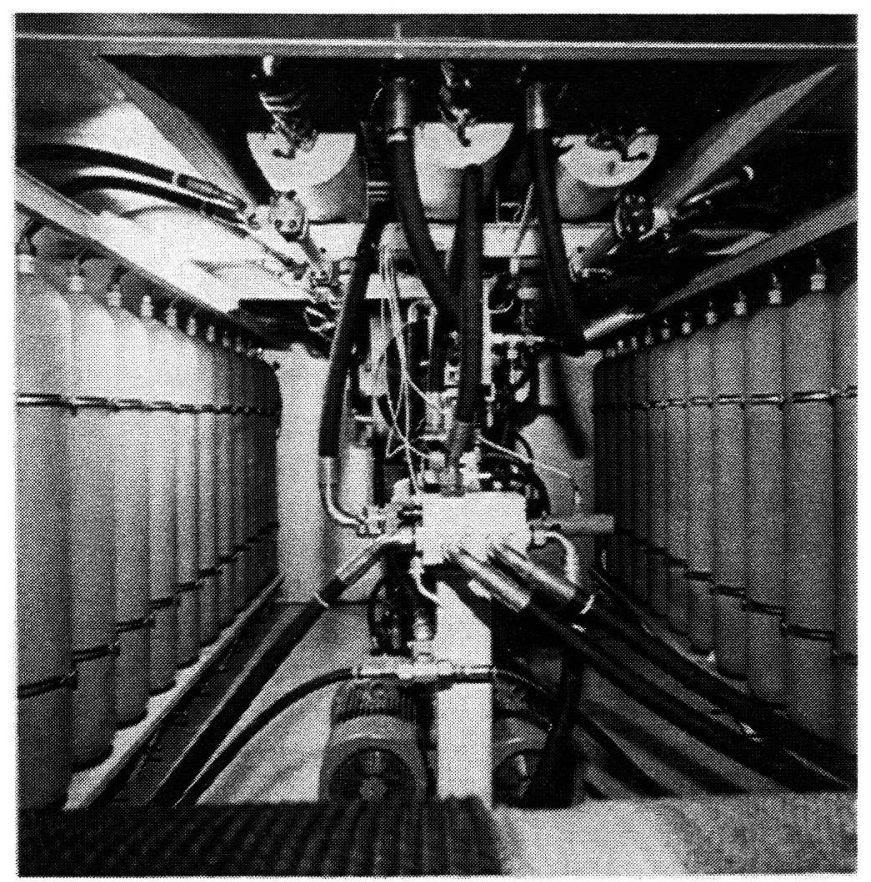

Eigure 9. Hydraulic pumps with electric engines, servo valve for speed control, Hydraulic accumulators and $24 \times 50$ litres nitrogen reservoirs 
force control system (figure 8 ). This system also takes care of length variations due to the ambient temperature.

The hydraulic motors are connected to three hydraulic accumulators charged by two pumps driven by electric motors $22 \mathrm{~kW}$ and $30 \mathrm{~kW}$ respectively which are started in sequence in order to limit the maximum current to available 125A. The accumulator system contains 300 litres and operates at pressures between 21500 and $31500 \mathrm{kPa}$. A traction or braking force of 70 $\mathrm{kN}$ can be applied at speeds up to $10 \mathrm{~m} / \mathrm{s}$. The speed control which is performed by a computer controlled servo valve is presently limited to $11 \mathrm{~m} / \mathrm{s}(40 \mathrm{~km} / \mathrm{h})$. The installation is shown in figure 9.

The accumulator power is only used in one direction. For retuming the track to starting position the pumps are feeding the motors directly which results in a track speed of about $0.3 \mathrm{~m} / \mathrm{s}$. The return travel time is about 3 minutes. The charging of the accumulators which takes place when the track is in starting position takes 3 minutes if the accumulators are empty. This is not the case after a normal run of $54 \mathrm{~m}$ and in this case the charging time is 2 minutes.

In case of an emergency stop the accumulators can be isolated from the servo valve by a special emergency valve. The oil in the accumulators is then dumped to the tank.

There are two separate emergency brake systems. One is a pneumatic brake system that acts with brake pads on the sides of the moving track and the other is a nylon rope brake that catches the end of the track if it runs beyond a certain point.

REFRIGERATION SYSTEM - The refrigeration system has three basic functions. The first is to enable quick generation of an ice surface on the moving test track. The second is to control the ice temperature independent of the air and the third to produce the desired air temperature.

The two first functions are achieved with a $110 \mathrm{~kW}$ refrigerator system where a refrigerant consisting of $50 \%$ water and $50 \%$ glycol is pumped from a $4 \mathrm{~m}^{3}$ tank to a pipe with nozzles in a channel below the test track and sprayed directly on the bottom surface of the test track when it is in its starting position. The channel seals against the test track and the refrigerant is subsequently collected in the channel and returns by gravity to the tank. Ice temperatures down to about - 20 degrees centigrade can be produced also in summertime.

The air temperature is controlled by several smaller refrigerator systems ranging from 10 to $2.5 \mathrm{~kW}$ with a total power of $25 \mathrm{~kW}$. One of the systems can also be used for heating the air if the outside temperature is lower than the desired temperature. The desired low ambient air temperature range of -20 degrees centigrade also in summertime is not yet reached and further improvements will be made.
ICE LAYING MACHINE - Water for making ice is added successively to the steel track from a self propelled battery powered trolley (figure 10 and 11) which runs from one end of the track to the other using the edges of the test track beam as rails.

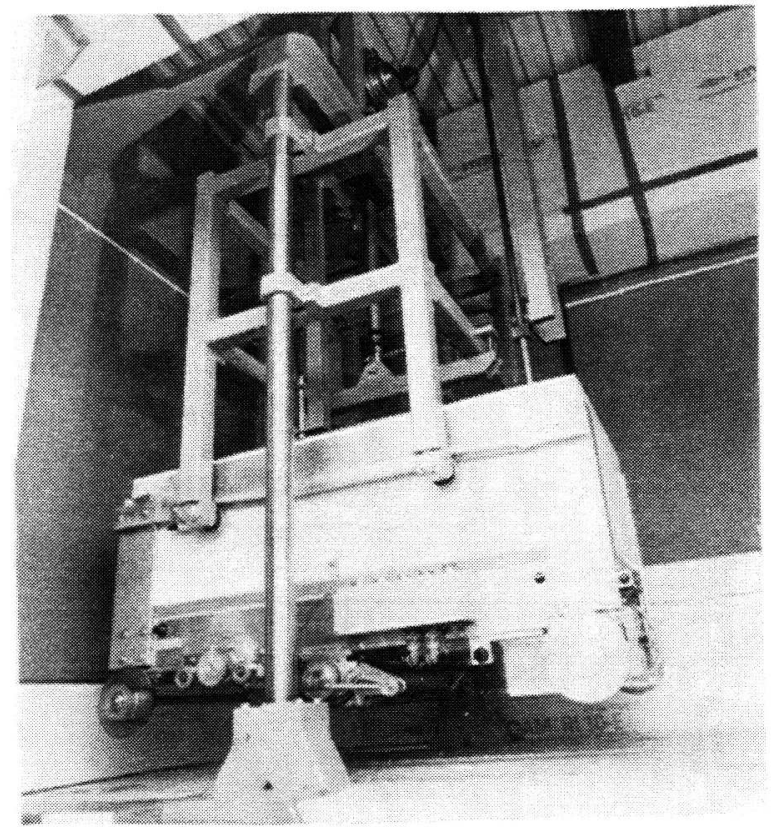

Eigure 10. Ice laying machine in rest position above the track tunnel

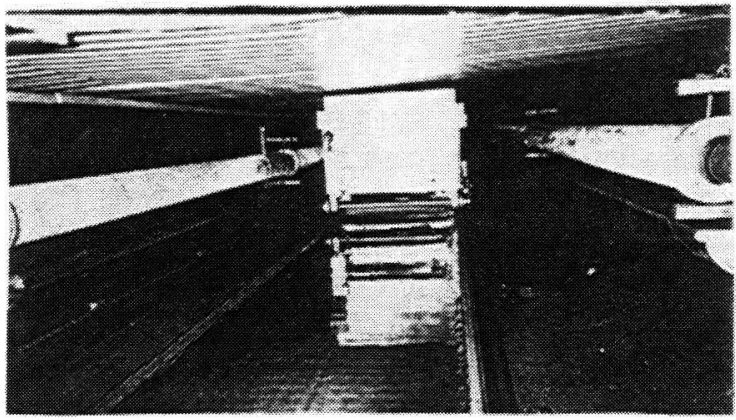

Eigure 11. The ice laying machine in operation on the track

Before starting this process the track temperature is lowered to about $-10^{\circ} \mathrm{C}$. The trolley runs at a speed of about $0,7 \mathrm{~m} / \mathrm{s}$ and reverses automatically. It applies a water film about 0.1-0.2 mm thick in one direction only . When the desired ice coating thickness has been produced the trolley is remotely stopped and hoisted into a storage room for recharging and refilling with water. It takes less than one hour to produce a new ice surface which is normally between 3 and $5 \mathrm{~mm}$ thick. The resulting surface is smooth and the ice is clear.

The ice is at present removed by melting the ice and vacuuming away the water. An ice cutting machine is under construction in order to get quicker ice removal especially in cold weather. 


\section{DATA REDUCTION AND PRESENTATION}

Data are digitally filtered to obtain smooth curves. Immediately after each test a diagram showing the time history of speed, wheel load, side slip angle, longitudinal slip, lateral friction and braking friction is automatically presented on the monitor screen (figure 12).

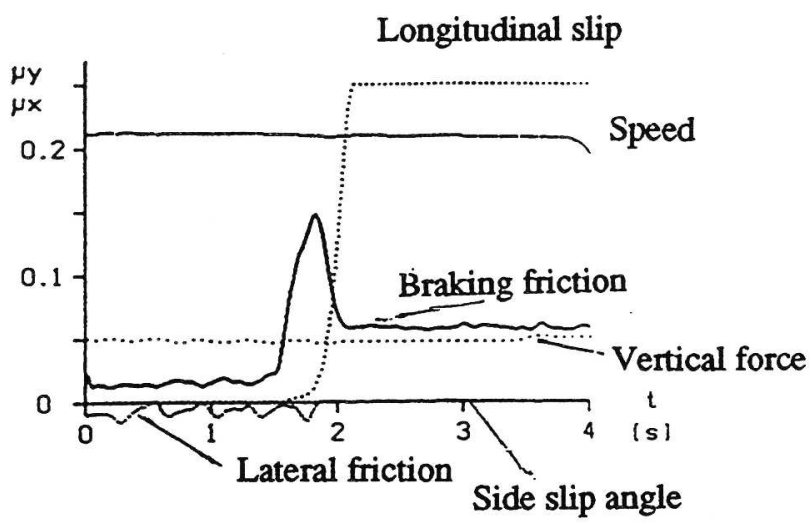

Figure 12. Time history diagram of the measured variables at a braking friction test.

\section{PERFORMANCE TESTING ON ICE}

BRAKING FRICTION - The braking friction of a tyre is characterised by the peak friction value for the rolling tyre and the friction value at locked wheel. The test speed is normally $30 \mathrm{~km} / \mathrm{h}$, although low speed measurements at about $2 \mathrm{~km} / \mathrm{h}$ are also used in special cases. In the tests the track is accelerated to the desired measuring speed in about 2 seconds. At a predetermined point of the test track the brake is applied at a rate that produces wheel lock in about 0.5 seconds. The wheel remains locked for the rest of the test run.

Before starting a series of tests on ice, the surface is polished four times with a special polishing tyre that is locked immediately after start. Then the same tyre is subjected to two normal test runs. The tyres to be tested are then run in series of three runs of which the first is a polishing run with locked wheel. The mean value of the results from the second and third runs is the result of the test series. As a rule each tyre is subjected to two test series and normalised against the results of a reference tyre that is run before and after each test series.

The results are documented in tabular form, specifying the maximum (peak) friction and the locked wheel friction calculated according to a slightly modified version of the US ASTM Standard E 1337-90. According to the standard the signals are digitised with $100 \mathrm{~Hz}$ and a running average from five values produced. The modification is that a further running average is produced based on 9 values which is then used to calculate the peak value according to the standard. The results are also shown graphically both in the form of friction as a function of time and in the form of friction as a function of longitudinal slip (figure 13).

LATERAL FRICTION - The lateral friction is measured in order to describe the steerability of the tyre. The maximum lateral friction and the lateral friction at $20^{\circ}$ side slip angle are used as characteristic values. The justification for the last mentioned value is that it indicates the violence of a lateral break away if the peak friction is passed. For optimum safety the $20^{\circ}$ value should deviate as little as possible from the maximum value.

On ice the maximum lateral friction has normally been reached at $5^{\circ}$ side slip angle.

The measurements are carried out at the same speed and in a similar manner as when braking but steering the wheel instead of braking. The $5^{\circ}$ side slip angle is reached after 1 second and $20^{\circ}$ after 2 seconds. The lower initial steering speed is motivated by the fact that the utilised friction increases rapidly in this range and that it takes a certain time to build up the lateral force due to the elastic properties of the tyre.

The results are documented in tabular form specifying speed, wheel load, maximum lateral friction and the associated slip angle and the lateral friction at $20^{\circ}$ side slip angle. The corresponding longitudinal friction utilisation due to rolling resistance is also recorded. The results are also shown graphically in the form of lateral friction and side slip angle as a function of time and in the form of lateral friction as a function of side slip angle (figure 14).

FRICTION FORCE MEASUREMENT DURING SIMULTANEOUS STEERING AND BRAKING -

This type of measurement is used to study the interaction between lateral and longitudinal friction. Each test is run at a constant side slip angle and the braking force is gradually applied so as to reach the maximum longitudinal friction in about $0.5-1$ second. By stepwise increasing the side slip angle, the lateral friction can be described both as a function of longitudinal slip at different side slip angles and as a function of slide slip angle at different levels of braking friction utilisation.

The results are presented in a similar way as in the case of braking friction, but with the addition of data on lateral friction. An example of graphic presentation is shown in figure 15.

RESULTS ON ICE - Measurements with truck tyres have been made on smooth ice and on ice roughened with a fine toothed scraper. Tyres of standard type with dimension 315/80 R 22,5 tested with a wheel load of $40 \mathrm{kN}$ on smooth ice polished by locked wheels at 


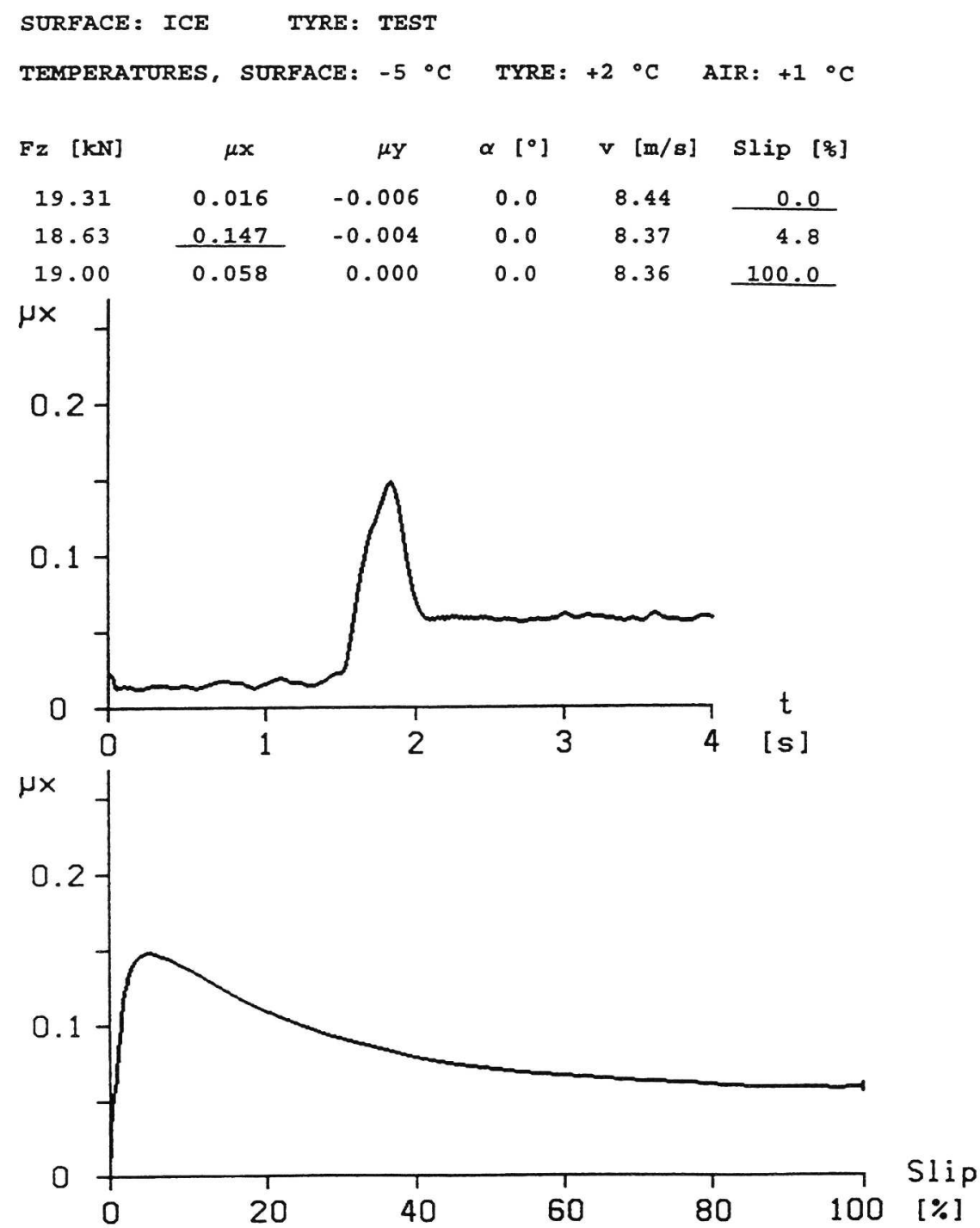

Eigure 13. Example of result from measurement of braking friction on ice with a $295 / 75 \mathrm{R} 22.5$ truck tyre at $19 \mathrm{kN}$ wheel load and 6.5 bar inflation pressure at $30 \mathrm{~km} / \mathrm{h}$

$-3^{\circ} \mathrm{C}$ have produced maximum values for braking friction down to $\mathbf{0 . 0 5}$ and locked wheel friction down close to $0.02 \mathrm{i}$. e. extremely low values. In these cases a minor roughening of the ice with the fine toothed scraper increased the maximum friction to about 0.2 and the locked wheel value to about 0.05 . More typical maximum friction for standard tyres on ice is 0.12 and for locked wheel 0.04 . Good winter tyres have substantially higher values especially for locked wheel with 0.07 as a typical value on smooth ice at $-5^{\circ} \mathrm{C}$.

Lateral friction measurements have shown similar results. On smooth ice maximum lateral friction down to 0.08 and $20^{\circ}$ side slip angle friction down to 0.04 has been obtained. Roughening of the ice in this case increased the lateral friction to 0.25 and 0.1 respectively.
HIGH FRICTION RESULTS - Tests have been carried out on the steel surface of the moving track with truck tyres of the dimensions 315/80 R 22.5 and 275/70 R 22.5.

Braking tests with wheel loads between 10 and 40 $\mathrm{kN}$ at $30 \mathrm{~km} / \mathrm{h}$ showed a decrease in friction with increasing load. The maximum braking friction decreased from 0.9 to 0.7 and the locked wheel friction from 0.7 to 0.4 . Lateral friction was measured in the load range from $10 \mathrm{kN}$ to $80 \mathrm{kN}$. The maximum lateral friction decreased with increasing wheel load from 1.0 at $10 \mathrm{kN}$ to 0.56 at $80 \mathrm{kN}$. At $40 \mathrm{kN}$ the maximum value had already been reduced to 0.6 .

Tests with combined steering and braking have also been carried out. An example from such measurements is shown in figure 15. 
SURFACE: ICE TYRE: TEST

TEMPERATURES, SURFACE: $-4{ }^{\circ} \mathrm{C}$ TYRE: $-2{ }^{\circ} \mathrm{C}$ AIR: $-3{ }^{\circ} \mathrm{C}$

$\begin{array}{ccccccc}\begin{array}{c}F z \\ {[\mathrm{kN}]}\end{array} & \text { ux } & \text { uy } & \begin{array}{c}\alpha \\ {[\%]}\end{array} & \begin{array}{c}\text { S1ip } \\ {[\mathrm{m} / \mathrm{s}]}\end{array} & \begin{array}{c}\mathrm{Mz} \\ {[\mathrm{Nm}]}\end{array} \\ 59.89 & 0.019 & 0.031 & \underline{0.0} & 8.10 & 0.1 & -38 \\ 59.09 & 0.018 & \underline{0.110} & 2.1 & 8.94 & 0.7 & -160 \\ 61.63 & 0.014 & 0.042 & \underline{20.0} & 8.75 & 19.3 & -133\end{array}$
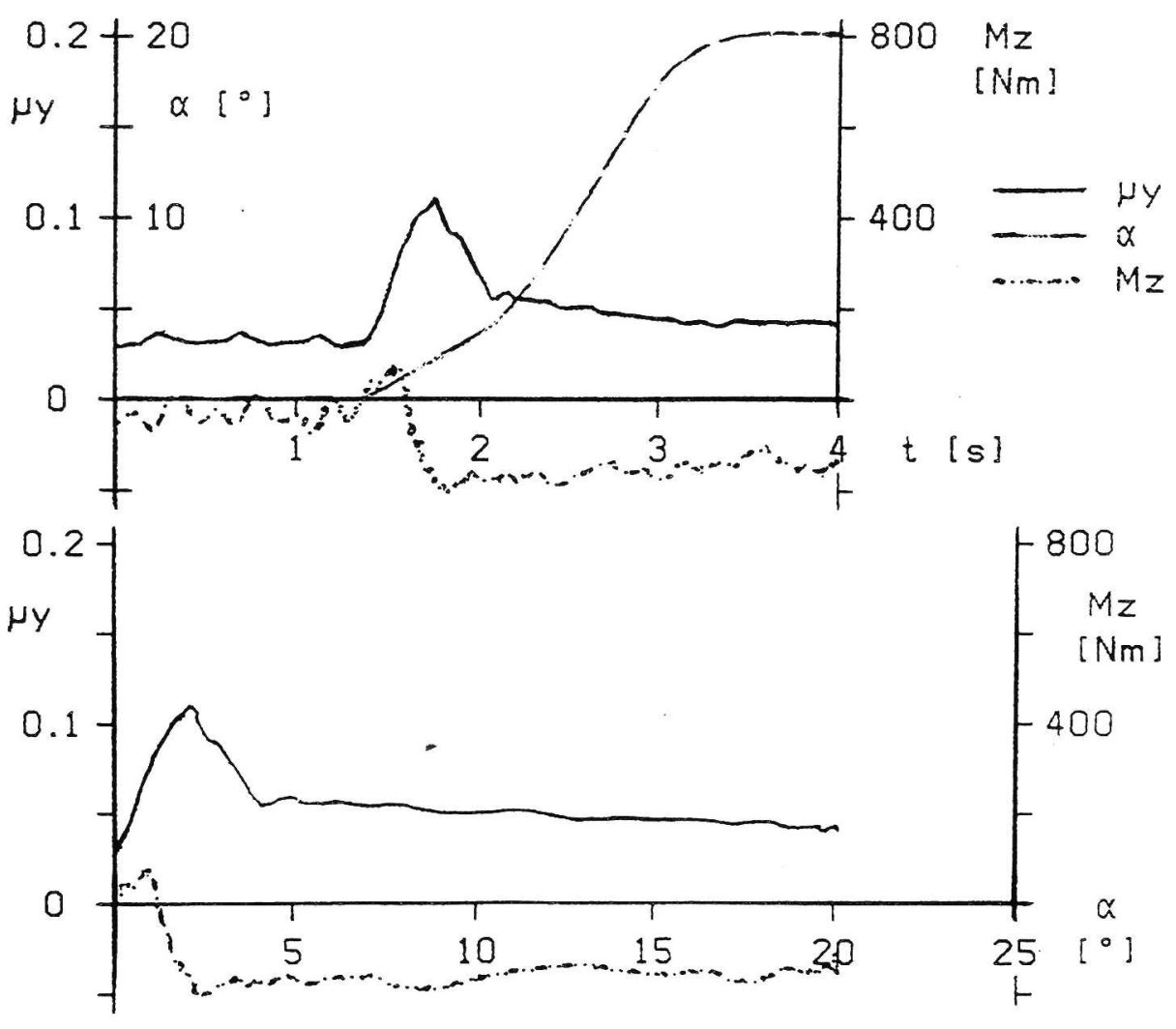

Eigure 14 Example of result from measurement of lateral friction on ice with a $380 / 80 \mathrm{R} 22.5$ truck tyre at $60 \mathrm{kN}$ wheel load and $8 \mathrm{bar}$ inflation pressure at $30 \mathrm{~km} / \mathrm{h}$.

RELIABILITY AND VALIDITY- On ice the repeatability of locked wheel braking friction is regarded as good. The repeatability of the maximum values is more variable depending on temperature and the type of tyre.

Repeatability on the steel surface was in all cases good despite tangible tyre wear and rubber deposits on the track.Concerning validity the results of the tests with truck tyres on lightly roughened ice agree well with the results from the full scale field tests with trucks carried out by VTI. In these tests the maximum value for braking

friction was between 0.09 and 0.23 and the friction at locked wheel between 0.07 and 0.09 . The maximum lateral friction obtained in full scale experiments is between 0.12 and 0.32 on smooth ice. The highest outdoor values were obtained at $-20^{\circ} \mathrm{C}$.

The results from measurements on the steel track are about equal to the average of what has been reported from measurements on dry asphalt and concrete roads. The results from car tyre testing also show good correlation with outdoor vehicle test results (1) 

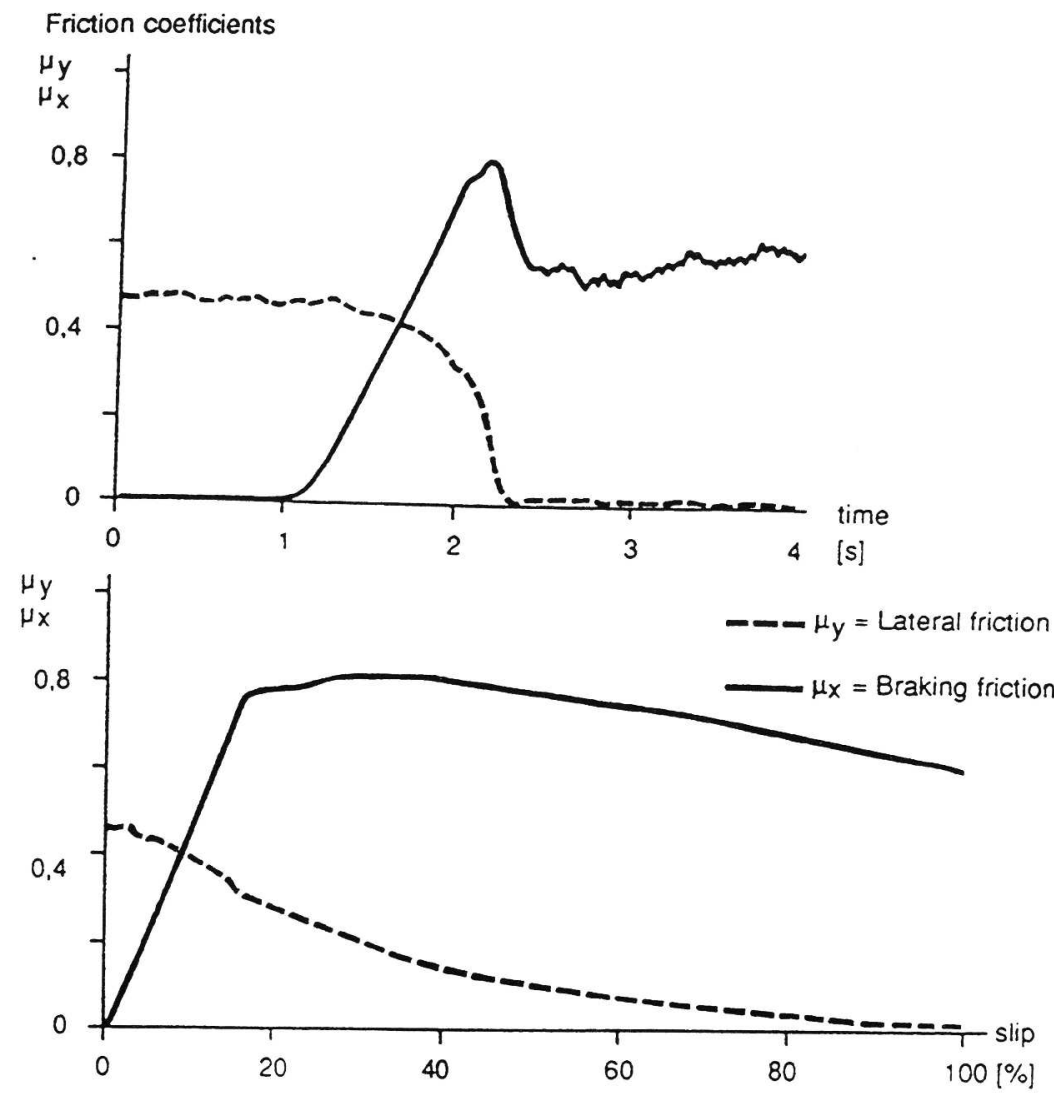

Figure 15. Example of result from measurement of combined lateral and braking friction with a $380 / 80 \mathrm{R} 22.5$ truck tyre on the high friction test track steel surface at $40 \mathrm{kN}$ wheel load and 8 bar inflation pressure at $30 \mathrm{~km} / \mathrm{h}$.

\section{SUMMARY AND CONCLUSIONS}

The friction between tyre and road is an important safety factor especially on icy winter roads. More information about the friction characteristics of tyres is needed. .Improvement of commercial vehicle safety is regarded as important.

1) A high speed flat bed tyre test facility has therefore been developed primarily for testing on ice.

2) High friction tests are also possible .

3) Braking and steering characteristics of heavy truck and passenger car tyres can be measured.

4) Results from heavy truck tyre measurements on ice and dry steel show good correlation with vehicle tests. Passenger car tyres have also been successfully tested.
Test facility data:

Maximum test speed $\quad 11 \mathrm{~m} / \mathrm{s}$ Test wheel load $\quad 0-100 \mathrm{kN}$

Braking force $\quad 0-70 \mathrm{kN}$

Lateral force $\quad 0-70 \mathrm{kN}$

Side slip angle $\quad 0-90^{\circ}$

Camber angle $\quad 10^{\circ}$

Side slip angular velocity $\quad 0-30 \%$

Ice temperature range $\quad 0--20^{\circ} \mathrm{C}$

Maximum wheel size approx. $1.3 \mathrm{~m}$ diam.

Ice coating capacity approx. $6 \mathrm{~mm} / \mathrm{h}$ at $-10^{\circ} \mathrm{C}$ track temp.

Effective measuring

time at max speed

about $4 \mathrm{sec}$

\section{REFERENCES}

1. Nordström, $O$ and Samuelsson $E$.

Road grip of winter tyres on ice.VTI Report No 354 (in Swedish with extensive English summary) Linköping, Sweden 1990 



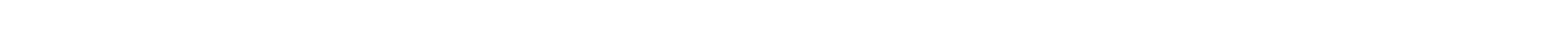
. . . - 




\section{do}

Swedish Road and
Transport Research Institute

Forskar för ett liv i rörelse.

Research for an active community.

Statens väg- och transportforskningsinstitut har

kompetens och laboratorier för kvalificerade forsknings-

uppdrag inom transporter och samhällsekonomi,

trafiksäkerhet, fordon, miljö samt för byggande, drift och underhåll av vägar och järnvägar.

The Swedish Road and Transport Research Institute has laboratories and know-how for advanced research commissions in transport and welfare economics, road safety, vehicles and the environment. It also has research capabilities for the construction, operation and maintenance of roads and railways. 